\title{
Jóvenes: trabajo y educación en la ciudad de Guayaquil ${ }^{1}$
}

\author{
Gardenia Chávez Núñez*
}

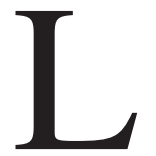

os chicos y las chicas no son solo esos "otros" seres extraños que hablan, piensan, sienten y se comportan de manera distinta y muchas veces chocante ante la mirada de la población adulta, son también y ante todo nuestros semejantes y compartimos el mismo mundo con todas las complejidades y conflictos actuales. La juventud es una de las tantas otredades que nos permite mirarnos y mantener vigente las interrogantes de ¿cómo convivimos y cómo queremos convivir con la diferencia siempre emergente? y, por tanto, con qué contenidos y cómo construimos las respuestas.

Este artículo pretende ubicar elementos, dichos por los propios jóvenes, para alimentar las respuestas desde la reflexión de los temas de trabajo y educación; y quizá, llegue a oídos receptivos. El cómo abordar la juventud, cada vez incorpora más elementos a ser considerados en este hecho, generalmente entendido desde dos entradas, la una como pasaje de la infancia a la vida adulta y la otra como actitud vital. Establecer los rangos de edad, los cambios biológicos, psicológicos, la extensión de la moratoria social, la incidencia de la pertenencia étnica, los cambios en las expectativas individuales y los sentidos sociales, las demandas del mercado, las formas comunicacionales, entre otras, presentan la complejidad de interpretar, comprender y explicar que pasa con la población que la denominamos jóvenes y qué rasgos contiene la

* Investigadora del Centro Andino de Acción Popular (CAAP). 
juventud. Operativamente y sin eludir o disminuir la complejidad anterior, el establecer márgenes de edad permite contar con un sector de población caracterizable, una base de información sobre ella que permite comparar y a su vez aglutinar los otros elementos. Así, en el Ecuador, la Ley de la juventud, aprobada en el 2001 establece el rango de edad de 18 a 29 años. A nivel internacional, según Naciones Unidas, la población joven va de los 15 a los 29 años incluyendo al grupo adolescente y estableciendo la diferencia de adultos-jóvenes a aquellos que se encuentran entre los 24 y 29 años ${ }^{1}$.

Hoy, todos y todas vivimos, de una manera o de otra, las profundas transformaciones producidas por los procesos de globalización evidenciados en las dos últimas décadas, y que son formas de la configuración de un nuevo orden mundial. Procesos marcados por la hegemonía de concepciones neoliberales y dados principalmente en la economía, el desarrollo tecnológico, la comunicación, la política y la cultura. La sociedad es ahora global y se reorganiza en todos sus ámbitos, la producción, el trabajo, la familia, la educación, las formas de socialización, entre otros, presentan cambios sin precedentes que nos desafían en su comprensión, formulación e implementación de acciones que permitan superar los efectos polarizados marcados de violencia, exclusión e inequidad.

En la relación de los procesos de globalización con el mundo del trabajo, operan los cambios generados por la aplicación de los avances tecnológicos en la producción, información y comunicación. Estos han descentrado las características anteriores de la organización del poder y las economías, ubicando el predominio del capital financiero y de la banca privada internacional sobre el campo productivo. La organización del trabajo se replantea bajo esta lógica y en

\footnotetext{
${ }^{1}$ En el estudio mencionado se consideró como parámetro la referencia internacional y en Guayaquil se realizaron 10 grupos focales con la participación de un total de 77 jóvenes entre 13 y 31 años de edad.
} 
medio de políticas de flexibilización y privatización que cambian drásticamente las anteriores formas de regularización, protección del empleo y en general la relación Estadosociedad.

Un elemento tradicionalmente vinculado al trabajo tiene que ver con la incidencia de la educación como factor que facilita el acceso al mismo y a las mejores condiciones para su desempeño. Sin embargo, en el marco de las transformaciones antes señaladas, la educación también ha modificado o acentuado varias de sus lógicas, para muchos no es accesible, para otros, ha dejado de ser una aspiración central y para importantes grupos ha dejado de tener importancia la buena formación profesional como condición del desempeño laboral posterior. En forma global hay un alto deterioro de la calidad de la educación, alta mercantilización y una seria dificultad de los responsables de las instituciones educativas de leer y responder a las transformaciones provocadas por los procesos de globalización.

En este contexto, sentido y alcances, los aspectos que siguen exponen diversas expectativas y percepciones de diversos jóvenes de la ciudad de Guayaquil, que están próximos o en medio de iniciar su vida laboral ${ }^{2}$.

\section{Percepciones sobre la situación económica y social}

La generalidad de la juventud participante en los grupos focales refiere a la situación económica de la ciudad de Guayaquil y del país en general, como negativa y difícil. En estas intervenciones no se aprecian distinciones marcadas si se considera el nivel de instrucción, la situación social, étnica, económica y de género de los y las participantes.

Las explicaciones centrales como causas o antecedentes de la mala situación actual son la crisis financiera, la

${ }^{2}$ Este artículo se limita a la información de los cinco grupos realizados a nivel de jóvenes, por lo que no se incluye la de los adultos jóvenes. 
dolarización, migración, corrupción e incremento de la inseguridad debido a la presencia de distintas formas de violencia y su gran frecuencia.

Hay visiones diferenciadas respecto de la posible mejora o agudización de la situación. Así, a menor condición económica, si son más jóvenes y con pocos o nada de estudio, la visión es más negativa y si es mejor la situación socioeconómica y el nivel de estudios la lectura atenúa la tendencia negativa y brinda más elementos de análisis. De todas maneras, la visión global está en un margen negativo por cuanto las posibles mejoras son vistas como inestables y condicionadas a medidas políticas y económicas sobre las cuales no tienen certeza de que se implementes de manera sostenida.

El impacto de la crisis económica en el nivel familiar e individual es fuerte para la mayoría, especialmente en el nivel de ingresos, capacidad adquisitiva y de ambiente de seguridad. El alcance de la afectación está marcado por las diferencias sociales, culturales y económicas. Lo anterior se expresa claramente en las intervenciones de los chicos y chicas, podemos ver cuatro grandes matices:

a) Para las familias y juventudes de estratos altos la afectación se expresa en la disminución del poder adquisitivo que restringe la plena satisfacción de sus necesidades básicas y/o complementarias, así como de proyecciones. Esto es, se afecta la holgura y el respaldo económico (capacidad de ahorro y acumulación).

b) Para las familias y juventudes de los sectores medios significó un empobrecimiento por pérdidas de trabajo y/o mayor dificultad de encontrarlo. La satisfacción de necesidades básicas se ven disminuidas.

c) En los sectores bajos o populares es un asunto de agudización de las condiciones de pobreza y exclusión.

d) Para el sector marginalizado es un asunto de sobrevivencia, de cómo garantizar alimentación y vivienda diaria. 


\section{¿Qué esperan de la vida?}

Las aspiraciones manifestadas por los y las jóvenes se enmarcan en grandes campos establecidos socialmente: estudiar, tener un trabajo y formar una familia. Sin embargo, los alcances de estas expectativas se ven diferenciadas según la pertenencia socio-económica.

Para el grupo de jóvenes de estratos socio-económicos más bajos y sin estudios, se observa una combinación entre sus expectativas, las condiciones en que viven y las posibilidades concretas de obtener lo que quieren, entre risas que advierten imposibilidad cuentan sus sueños ya impregnados de sus vivencias "Yo quiero ser arquitecto.... yo quiero ser presidente para ayudar a los de la calle... abogado para sacar a los presos..."3. Posteriormente, expresan aspiraciones "más realizables" considerando su situación de grupo excluido, "la gente, la mayoría quieren ser futbolistas, le hacen mucho a la pelota... Queremos cambiar y ser mejores en la vida"4. Los jóvenes de este grupo, se miran a futuro oscilando entre sus deseos de cambiar y las demandas hacia el resto de la sociedad donde encuentran pocas oportunidades:

Estando viejo qué voy a hacer, cambiar y que nos respeten los derechos humanos. Que nadie nos golpee...nuestro único espacio que tenemos, nuestra casa "El Patio mi Pana", armamos relajo igual nos reciben (GFA1).

En el segundo grupo caracterizado por tener estudios primarios y de estratos medios y populares, se observa la importancia de conseguir un trabajo estable como base para sostenerse personal y familiarmente:

\footnotetext{
${ }^{3}$ Integrantes del GFA1.
}

${ }^{4}$ Integrante del GFA3 
Tener mi familia, tener un trabajo fijo para poder mantenerme, yo creo que todos estamos de acuerdo que lo primero es tener un trabajo fijo para ver si se puede formar un hogar o incluso ayudar a los padres mismos, porque ya los padres de uno no siempre van a estar ahí trabajando, igualmente no, tener un trabajo fijo, y de esa manera teniendo ya un trabajo fijo poder formar una familia y asi devolver todo a nuestros padres (GFA2a).

También se observan aspiraciones y dificultades en torno a los estudios y campos de acción que les gusta pero que no siempre accesibles y/o "rentables" económicamente:

... para poder tener un título se debe viajar y para eso también se necesita dinero para poder solventar los gastos, estudios, dinero allá. Por ejemplo este país no es desarrollado sino un país tercermundista. Mi sueño por ejemplo es ser músico, pero en este país no da ya que siempre se ve a músicos famosos en Europa y Norte América. Porque aquí si sale algo hay la novelería y por eso en este país no se puede tratar de superar, ya que siempre prefieren otras cosas que lo de aquí, lo extranjero (GFA2b).

En los grupos tercero y cuarto, que pertenecen a un estrato socioeconómico más alto y con mayor nivel de estudios, es clara la diferencia en el campo laboral, pues las expectativas no se limitan a emplearse sino a tener su patrimonio "Lo que todo mundo sueña, tener a su familia, una empresa, y sacar adelante a tu familia".

Como se puede observar, las expectativas de vida comunes toman rostro de acuerdo a las condiciones específicas de los grupos y es a las particularidades que habría que acercarse para la interpretación y comprensión de la juventud. También los y las chicas se miran reconociéndose en la heterogeneidad y en los varios problemas que atraviesan, señalan:

\footnotetext{
${ }^{5}$ Integrante del GFA2a.
} 
"Habemos jóvenes que en esta época queremos gobernar a sus padres, quieren hacer lo que les da la gana (cambio de la autoridad adultocéntrica)...no quieren estudiar (descentramiento de la educación)... La juventud se ha alzado de una forma fatal porque hay chicas, madres solteras y son como de 13 o 17 años que salen embarazadas $y$ eso es feo (cambios en hitos vitales)... Cómo jóvenes ahora nosotros vivimos rápido (cambio en la noción del tiempo), la mayoría de las madres son de 13, 14 años... Hay algunos jóvenes que dicen: no si a mí me vale (cambios en sistemas de valores). Ahora el pandillerismo ha arrasado con todo... (varios integrantes del GFA2b).

Ubican que el entorno y los cambios que se da en la institución de la familia repercuten en la juventud y en el aparecimiento de los problemas antes señalados:

Pienso que los problemas que hay de madres solteras, las pandillas es en gran parte por la desintegración familiar. Una vez que un padre y una madre pongan autoridad en la casa, en mi barrio casi nunca hay autoridad del papá y de la mamá a veces el papá está por un lado y la mamá por otro (GFA2b).

En este panorama, los sueños individuales se relacionan con las expectativas del padre y la madre; de la información obtenida, se observa que las chicas y chicos leen claramente lo que sus progenitores esperan: “... vernos ya formados como personas, como ciudadanos, no sé, ese es el anhelo de los padres yo creo y común de todos, por eso trabajan y tratan darnos hasta lo imposible a todos, o sea vernos ya realizados"6.

En unos casos hay articulación entre los sueños personales y las expectativas familiares: "Esos son mis sueños de ayudar a mi familia eso si de tener un buen recurso económico para poder sacar a mi familia de donde está, porque 
eso es lo que más quiero que mi familia se sienta orgullosa de mí"'.

En otras situaciones se ubica contradicción, especialmente en la mirada de que profesión brinda mejores ingresos económicos: "... cuando yo entré al curso de actuación a mi mami casi le da un yeyo (un infarto), no es justo, a veces quieren hacer de nosotros un espejo, a veces ellos quieren que uno sea lo que ellos quieren que sea... es una competencia y no nos sentimos apoyados por nuestros propios padres"8.

También están presentes los elementos de autonomía respecto del ámbito familiar: "Yo no quiero trabajar en donde trabaja mi mamá sino salir de ahí, ponerme algo que sea mío, quiero hacer algo nuevo que sea mío" .

Se puede observar una tendencia relacionada con el nivel socio-económico de las familias de los y las jóvenes. A más bajo nivel afloran más comentarios, presiones y/o dificultades respecto de la profesión que deberían optar hijos e hijas. Entre los elementos que inciden es el esfuerzo que realizan padre y madre por brindar educación, la posibilidad de que "mejoren" y la relación con determinadas carreras que se miran como rentables. En este contexto el respeto por los gustos, opciones y decisiones de hijos o hijas no es lo prioritario. De otra parte, en los estratos más altos, al contar con un nivel básico asegurado y mejores opciones, el ambiente es más propicio para el respeto a las preferencias personales.

Si bien no es objeto de este estudio mirar las transformaciones de las expectativas, si cabe señalar que no se percibe cambios substanciales en el tipo, sino en la forma de realizarlas. Por ejemplo, para quienes estudian el formar

\footnotetext{
${ }^{7}$ Ídem.

${ }^{8}$ Integrante del GFA3.

${ }^{9}$ Integrante del GFA3. 
una familia es posterior a obtener un título, para los que no, más bien adelantan esta decisión. En el trabajo y estudio también hay cambios, como se verá a continuación.

\section{¿Qué esperan en lo laboral y cómo se miran a futuro?}

En el marco de las expectativas de vida, el trabajo lo ven como central pues éste permite la satisfacción de las otras. Las aspiraciones laborales de los chicos y chicas no se dan al margen de las características de su situación y del entorno.

Un primer aspecto básico es el acceso al trabajo. Para el primer grupo, por su condición de exclusión, contar con un trabajo cobra la fuerza de una petición al conjunto de la sociedad, hace referencia a la responsabilidad que esta tiene con ellos y a su vez, condición para cambiar el tipo de vida que llevan: "Quisiera que nos den trabajo y empleo, tenemos derechos para que nos respete la ley y un buen trabajo nada más...cuando uno esté trabajando, no robar en los carros"10. En el segundo grupo, ubican el temor a encontrar un trabajo a pesar de contar con estudios secundarios, pues éstos no son suficientes en el ambiente competitivo "... o sea, no es incorporarse como se piensa, que uno sale del colegio con el título bajo el brazo y ya lo van a decir: venga a trabajar, entonces es bien difícil eso"11. En los otros dos grupos, el acceder a un trabajo se relaciona con las mejores situaciones y oportunidades familiares y de su entorno, las aspiraciones a más de "encontrar trabajo", incorporan las cualidades de este: "Mi meta es ser presidente o gerente de una multinacional, pero de afuera"12.

En forma general hay la percepción de que la condición económica incide directamente en el acceso al trabajo: “... las

\footnotetext{
${ }^{10}$ Integrantes del GFA1.

${ }^{11}$ Integrante del GFA2a.

${ }^{12}$ Ídem.
} 
personas que por lo general poseen dinero, siempre tienen mas facilidades de adquirir un trabajo, ya sea por un contacto o cualquier cosa, siempre van a tener más facilidades que una persona pobre"13.

La estabilidad y seguridad en el trabajo es una idea constante y común a todos los grupos. En unos se expresa por encontrar un empleo con esas características: "Espero conseguir ya un trabajo seguro, ya con el título en la mano..."14. En otros, la preocupación es por mantener el trabajo. En los estratos más altos la estabilidad y seguridad se relaciona a crear y/o desarrollar su propia empresa o negocio y que marche bien.

Las ideas de estabilidad y seguridad no siempre implica permanencia en el mismo trabajo, más bien se interrelaciona con la aspiración de vivir distintas experiencias: "No me gustaría solamente limitarme a un solo trabajo sino tener experiencias en diversas áreas para poder desenvolverme y enseñar a otros que también se desenvuelvan"15.

Otra expectativa es la posibilidad de articulación del trabajo a otros ámbitos vitales de la vida, vistos como su opuesto. Valoran el aspecto de diversión, la amistad, espacios de socialización:

O sea, las cosas no hay que decirlas, por ejemplo, que ya terminas el colegio, te vas a dedicar a trabajar, y yo digo chuso(expresión propia de estos jóvenes) no, o sea que no cae, la cosa es trabajar y divertirse a la vez, tener todavía las relaciones con tus amigos pasarla bien no, o claro también ser responsable con el trabajo, o con la familia, o con los padres mismo, saber administrar el tiempo, para poder hacer más cosas más responsables (GFA2a).

Se advierte la dicotomía entre juego/diversión y trabajo, se puede observar entre una mirada adulta del traba-

\footnotetext{
${ }^{13}$ Integrante del GFA3.

${ }^{14}$ Ídem.

${ }^{15}$ Integrante del GFA2b. 
jo (seriedad, responsabilidad, no diversión) y una mirada juvenil que demanda el nexo.

Las expectativas laborales en el tercero y cuarto grupos, son más abarcativas, incluyen aspectos de identidad, desarrollo profesional, expansión económica, ampliación de horizontes y fronteras, se miran:

Buscando un socio para poder emprender una empresa, trabajarlo para llegar a esa meta. Y en otro país, teniendo mi contacto (GFA3).

Sobretodo hacer carrera, siempre uno aspira a una empresa grande en donde pueda crecer profesionalmente y laboralmente, formar parte de ingresos, formas positivas, experiencia, conocimientos o sea todo, uno espera eso de una empresa, o sea crecer juntos con la empresa (GFA4).

\section{Percepciones sobre el mercado laboral y los jóvenes}

Las percepciones en torno al mercado de trabajo en general, se enmarcan en la crisis económica, social y política que vivió y vive el país:

No hay empleo, para una vacante le llegan cien o doscientas carpetas... es decir que escogen a gente muy preparada, no solamente a gente que sale del colegio, y que obviamente está en sus primeros pasos laborales, sino de gente que tiene ya una carrera terminada o de personas que han estado desempeñándose en alguna otra institución pero que han cerrado por la crisis económica, o bancaria, entonces se ve mucha buena mano de obra desocupada, o subocupada haciendo algo en un empleo informal (GFA4). 
Ahora último se ve que alguien compra mercadería y se pone a vender, y saca ganancia de lo que venda, porque no puede conseguir un trabajo estable, porque no puede conseguir un trabajo en lo que ha estudiando, en lo que se ha especializado... muchas veces vemos manejando taxis a ingenieros, a médicos, no sé, vendiendo en las calles a abogados, no sé, es muy difícil encontrar un trabajo estable hoy en día... (GFA2a).

Lo que miran en su entorno es un cúmulo de situaciones adversas: a) falta de empleo; b) crecimiento del trabajo informal; c) ingresos bajos; d) muchas personas buscan más de un trabajo para completar los ingresos que requieren; e) extensión de la jornada de trabajo; f) inestabilidad laboral; g) más exigencias en la formación, experiencia y presencia personal; $y, h$ ) una tendencia en las familias de necesitar que más miembros aporten económicamente. En suma, la juventud percibe un ambiente con múltiples obstáculos, más exigencias, muy competitivo y con menos oportunidades. Al ubicarse ellos en dicho ambiente mencionan los siguientes aspectos:

La experiencia requerida es una constante en las intervenciones y los jóvenes se miran en desventaja, por un lado por el tipo de formación que reciben en los establecimientos educativos y por otra por la misma situación de iniciarse en el mundo del trabajo: "Se nos va a hacer muy difícil, ya que en la actualidad siempre para un trabajo piden personas experimentadas, y nosotros recién saliendo, se nos va a hacer muy difícil..."16. Además, está la exigencia pero no las condiciones educativas ni laborales que permitan ganar experiencia: "Mínimo te piden algunos años de experiencia, pero cómo uno va a tener experiencia si ni

\footnotetext{
${ }^{16}$ Integrante del GFA2a.
} 
siquiera le permiten trabajar. Uno no va a ganar la experiencia de la noche a la mañana"17. La experiencia no solo es un requisito, también es base para mantenerse en el puesto: “... ya que si nosotros vamos a un trabajo a reemplazar a una persona tenemos que rendir, sea más o igual que la persona que salió, pero al no tener la experiencia necesaria, pienso yo que eso sería uno de los problemas que podemos afrontar"18.

Los empleadores, cada vez más especifican rangos de edad, lo que constituye oportunidad o exclusión para unos y otros, esto es para jóvenes y adultos: "... es que usted ve en el periódico, quiere buscar un anuncio, y todos dicen la edad fija de 25 a35 años a lo mucho 40 y una persona de más de 40 años es imposible que trabaje y una de menos también"19.

Los obstáculos se diferencian según los estratos socioeconómicos; así, para el primer grupo, hay límites básicos como es la documentación personal: "No tenemos papeles, no tenemos documentos, cédula, partida de nacimiento, récord policial"20. Para los/as jóvenes que no tienen estudios o llegan hasta secundaria la exigencia de formación es un limitante serio: "Lo mínimo que nos piden es el bachillerato. Hasta para barrer en las calles de Guayaquil te piden el bachillerato o si no te toca ir a vender frutas, naranjas o algo asi"

Perciben que por la condición de ser jóvenes, están expuestos a situaciones de explotación: “... y si nos llegasen a escoger, o sea, pienso yo que uno de las cosas que nos puede pasar es que nos exploten, al ser jóvenes y por la necesidad de un trabajo... eso pienso yo que sería uno de los riesgos que nos tocaría afrontar"22. Se añade la inestabilidad e inseguridad en el trabajo, más si son jóvenes que aún no tie-

\footnotetext{
${ }^{17}$ Integrante del GFA2b.

${ }^{18}$ Integrante del GFA2a.

${ }^{19}$ Integrante del GFA3.

${ }^{20}$ Integrante del GFA1.

${ }^{21}$ Integrante del GFA2b.

${ }^{22}$ Integrante del GFA2a.
} 
nen la mayoría de edad. Cabe recordar que en el país está permitido el trabajo desde los 14 años:

Sí, hay mucha gente que necesita un trabajo. Un primo mío trabajaba en una empresa de productos lácteos y era asistente de la familia, trabajó gran parte del mes y lo botaron. Le pusieron de excusa que era menor de edad y lo botaron. Ganaba lo suficiente, lo cogieron para trabajar sin contrato y tuvo que salir, sin temor alguno le dijeron usted está despedido (GFA2b).

La expectativa de contar con un trabajo propio es vista como un mecanismo para evitar despidos y otras situaciones adversas:

... yo creo que lo mejor es tener un negocio propio estable... en otro tipo de trabajos estás propenso a miles de cosas, que le despidan... como ya no le ven tan joven ya no rinde igual lo despiden y cogen una persona más joven y con más experiencia que les va a rendir más, es por eso, sería mucho mejor tener un negocio propio, porque así incluso ya estarías pensando en el futuro de tus hijos, ya por ejemplo tu acá ya te sientes cansado, ya un hijo puede coger el mando, dice el negocio, incluso él ya no sería un empleado sino jefe de un propio negocio y cogería el mando, o sea también pensar en el futuro de un hijo, claro. (GFA2a).

La idea de trabajo por cuenta propia, cambia substancialmente varias concepciones y prácticas anteriores; por ejemplo, el acceso, estabilidad y protección en general del trabajo cambian de lugar, ya no sería el Estado quien deba garantizar, sino las condiciones y dinámica socio/eco- 
nómica. En la ciudad de Guayaquil es generalizado que desde los más diversos sectores se plantee el emprendimiento, las micro empresas y micro negocios como la solución a la situación actual. En esta visión, el Estado, la educación y los distintos sectores deberían aunar esfuerzos en este sentido.

Las percepciones de las relaciones laborales entre adultos y jóvenes se manifiestan en dos sentidos, hay quienes miran competencia y riesgo: "... bueno buscar gente joven es competencia para ellos... ven que las personas están avanzadas de edad y ellos son los primeritos que les van a quitar el puesto"23. Otros jóvenes opinan que no hay mayor competencia, puesto que hay actividades diferenciadas tanto para adultos como para jóvenes, permitiendo la complementariedad. También manifiestan que los adultos les enseñan varias cosas a los jóvenes, que por estar empezando sus vidas laborales, las desconocen. Hay también la relación extrema de no ver el mínimo apoyo: "los adultos son huesos, son perros, son tacaños usted les va a pedir una moneda y le dicen no tengo, te dicen anda a trabajar no tengo. Estamos discerniendo la verdad, la plena, la plena"24.

\section{Experiencias de trabajo previas}

La mayor parte de jóvenes que estudian cuentan con experiencias laborales previas o más precisamente paralelas. Si bien, se puede observar una relación con el estrato socio-económico, la tendencia parece ser generalizada, de las personas participantes son un pequeño grupo que se dedican solo a estudiar y que pueden continuar hasta el final solo con el financiamiento familiar. El combinar traba-

\footnotetext{
${ }^{23}$ Idem

${ }^{24}$ Integrantes del GFA1.
} 
jos y estudios, parece ser una estrategia que les permite apoyar a las economías familiares, iniciar sus propias experiencias laborales y contar con ingresos que abren el camino para una cierta independencia económica que les permite satisfacer sus particulares consumos.

Hay que ganarse la vida, no hay que vivir como quien dice de vago. En las vacaciones he trabajado de mesera y en cierta forma es como vivir rápido, porque tú aprendes cómo la gente piensa, lo que quiere, lo que desea. Pero en este momento la gente anda más detrás del dinero. El jefe donde yo trabajaba era muy avaro, deseaba mucho dinero y daba poco y recibía bastante. Inclusive trabajé tres semanas y me despidió porque dijo que no tenía dinero para pagarme. Son cosas que te ayudan para poder desenvolvernos en otros campos de trabajo (GFA2b).

En los itinerarios de las experiencias de trabajo, se reflejan varias características del mercado laboral para jóvenes; así se puede ver las siguientes.

El período de prueba es la primera vivencia que deben pasar, es un momento en el que la juventud se encuentra en condiciones de vulnerabilidad ya que los parámetros de evaluación son ampliamente subjetivos e incluso los 3 meses acostumbrados se convierten en una estrategia para evadir una contratación estable:

Los ponen primero a prueba los tres meses si les gustó sigue por tres meses más hasta que ya, te dejó sin una contratación (GFA3).

El inicio de la juventud en actividades laborales es cada vez más temprano y en distintas ocupaciones, "en lo que se presente": 
He trabajado de muchas formas, desde los trece años trabajé marcando fichas en un nintendo, de ahí cuando puedo tengo que ayudarle a mi mami a trabajar en lo que es comercio. A veces me ha tocado ponerme a vender con mi mami en la esquina como tortillas y esas cosas (GFA2b).

Manifiestan que hay abuso en el trabajo por la condición de ser jóvenes:

Antes era menor de edad. Ahora soy mayor de edad. Si me han dado la oportunidad, pero a veces te exigen mucho para hacer cosas que ni ellos mismo hacen, pero sin embargo hay que saber pelear por la vida (GFA2b).

Yo últimamente busqué trabajo porque salí del anterior, pero una de las cosas que, yo los veía como que abusaban, de las experiencias que de repente tenga, de que no te conocen, así sea alguien que de repente te conozca, sino que tú vas libremente a alguien particular a pedir trabajo y te pagan lo que quieran, no realmente valoran lo que tú estudias o para lo que estas preparando y te ofrecen cualquier cosa, y el inglés también en otro trabajo era una de las cosas... Súper injusto porque te ofrecían tonteras, y aparte del impuesto y las cosas y las expectativas que te ofrecían nada que ver, y otra cosa es que ahora muchos de los empleadores están usando el método de la tercerización, que a ningún empleado le beneficia en realidad solamente le beneficia al empleador, entonces digo si realmente uno trabaja es porque quiere y porque necesita (GFA4). 
Para la mayoría las primeras experiencias no son una buena entrada al mundo laboral, están marcadas por hacer lo que les toca y no lo que desean hacer, sufren explotación, inestabilidad e inseguridad (por lo general no tienen contrato ni seguridad social). A esto se suma la forma de conseguir trabajo, que tampoco es un motivador de desarrollo personal.

\section{¿Cómo piensan conseguir trabajo o cómo lo han hecho?}

Un primer elemento: los y las jóvenes de estratos medios y bajos, expresan una predisposición a "enfrentar" las dificultades, de abrirse camino: "... sinceramente yo termino de estudiar no, yo trabajaría de cualquier manera no, o sea no importa cual sea el trabajo, bueno con tal de ir ganando experiencia" 25 . Otros chicos y chicas dicen: "Empezaría por donde se pueda... Me pondría a trabajar de mimo... podría poner se hacen trabajos en informática... Me fuera primero por lo que más me gusta y por lo que mejor se hacer y si alguien me pide papeles le diría, yo le rogaría que primero mire lo que sé hacer y que después me dijera si está bien o mal"26. Otros con cierto pesimismo ubican el "costo" que deben pagar "uno cuando recién comienza, necesita un hueco para uno ganar experiencia, uno de la noche a la mañana no se va a subir como la espuma. Primero tiene que ir por lo básico, me imagino uno tiene que empezar por un puesto normal, claro para todo hay que sufrir para llegar a ser alguien bien importante, pero eso aquí no se da, es decir no hay oportunidades para los jóvenes" ${ }^{27}$.

\footnotetext{
${ }^{25}$ Idem.

${ }^{26}$ Integrantes del GFA2b.

${ }^{27}$ Ídem.
} 
Mientras que la juventud de sectores más acomodados cuenta con oportunidades desde la propia familia, mediante sus empresas o negocios y de su entorno, el punto para ellos no es empezar por lo que sea, se trata más bien de ubicar algo adecuado por donde empezar.

Frente a las preguntas, ¿cómo piensan encontrar trabajo? o ¿qué han hecho para encontrar trabajo?, la respuesta generalizada es "buscando", esta expresión encierra una macro estrategia o un conjunto de ellas, que se puede interpretar como un individuo moviéndose en distintas direcciones, con muchas personas y usando formas variadas. El buscando se expresa en acciones como poner voces que circulan en redes familiares y de amistad o en recorridos por la ciudad: "A través de amigas o letreros que dicen se necesita señoritas para meseras, para atender"28; también intentan con el procedimiento de distribuir hojas de vida "... ingresan sus curriculums en varias partes, y ahí donde le sale, ahí trabajan"29.

Como parte de esa búsqueda permanente, la "palanca" y el "padrinazgo" son las estrategias más utilizadas y efectivas; entendidas como formas de apoyo de alguien con influencia que recomienda a la persona interesada o que la 'apadrine'. El peso está en la recomendación, influencia o tutela, mas no en las cualidades y formación profesionales y/o experiencia: "Más se consigue trabajo por una palanca o por una ayuda a que por uno mismo, o sea es bien difícil que algún día yo consiga trabajo solo por el currículum, siempre es mi amigo el que me lo consiguió o cosas así..."30. Al respecto los chicos y las chicas plantean que esta forma no es la mejor y la critican fuertemente porque significa corrupción, pero al mismo tiempo reconocen que es lo que impera en el país.

\footnotetext{
${ }_{28}$ Ídem.

${ }^{29}$ Integrante del GFA2a.

${ }^{30}$ Integrante del GFA3.
} 
Las empresas tercerizadoras son ahora un mecanismo para la ubicación laboral, las mismas que no son bien vistas:

...a pesar de que uno de los únicos países latinoamericanos en que todavía se reparten utilidades es en el Ecuador, pero si todavía la hay se la debería respetar y una de las cosas de las tercerizadoras por la que fueron creadas, es justamente para eso, para que las utilidades se las lleven ellas, porque ahí todos los beneficios de ley todo le pagan, pero en el momento de repartir las utilidades ya no le reparten a los empleados ${ }^{31}$.

Las formas de obtener trabajo no contribuyen ni a facilitar el ingreso de los y las jóvenes y tampoco constituyen formas de aprendizaje de pautas transparentes en las relaciones de trabajo y sociales.

\section{Migración y trabajo}

"Es el sueño de cualquier persona que no tenga la oportunidad de estudiar, es emigrar, pero mientras esté aquí, haciendo de todo un poco"32.

El tema de la migración es ubicado como un hecho importante. La emigración de los últimos cinco años, principalmente a EE.UU. y Europa, es mirada como respuesta a la crisis generalizada del país y que en el ámbito económico/laboral permitió: a) disminuir el impacto de la desocupación, b) acceder a otras oportunidades de trabajo, c) mejorar niveles de ingreso y/o de vida $y, c)$ existencia de reme-

\footnotetext{
${ }^{31}$ Integrante del GFA4.

${ }_{32}$ Ídem.
} 
sas que aportan a las economías familiares y la economía nacional por cuanto son el segundo rubro de ingresos de divisas.

La inmigración, especialmente de población colombiana y peruana es vista como un factor que aumenta la competencia laboral:

Definitivamente conseguir empleo es bastante peleado sobre todo por la parte del incremento de la migración de Colombia y de Perú, ahora por cada puesto vamos a pelear siempre con alguien de Colombia o de Perú, tenemos todavía la idiosincrasia y la ideología que el extranjero es mejor que nosotros (GFA4).

Esta percepción es repetitiva de la visión generalizada en el país, a la cual se suma la mirada sobre la población colombiana como factor directo del aumento de la inseguridad. La falta de políticas migratorias y el manejo de los medios contribuyen a propagar la visión de la inmigración como un hecho negativo y reproduce la visión no recíproca de querer apertura cuando la población ecuatoriana va a otros países y de cerrar las puertas cuando ingresan personas de otras nacionalidades al país.

\section{Hombres, mujeres y trabajo}

La mayoría de jóvenes perciben que las mujeres tienen mayor acceso y presencia en el mercado laboral: "De repente porque las mujeres, son más en ciertos aspectos son como más organizadas, más comprometidas... dicen que los hombres son más viscerales o no sé... de repente las mujeres están logrando hacer más carrera" ${ }^{33}$.

${ }^{34}$ Ídem. 
En algunos campos, como ventas, las oportunidades son mayores para ellas, aunque esto es relativo ya que se relaciona con la edad y estado civil de las mujeres, si son adultas y con familia las posibilidades disminuyen:

En ventas hasta de 25 años, en eso sí hay discriminación, y en general para la contratación si hay bastante discriminación en las empresas ya cuando ven, más que todo en la mujeres si es de 34 años y tiene una familia que el hijo se le enferma que no viene porque la escuela, o que si que no, entonces sí va habiendo un poquito de discriminación en el momento de la contratación (GFA4).

En las relaciones laborales cotidianas hay experiencias de cambios importantes: "En mi caso el trato era igual, hombres, mujeres, igual o sea, en mi trabajo le daban igual a una mujer o un hombre, no había un trato ni de discriminación ni especial, se trataba igual, como un empleado más"34.

En los estratos más altos expresan claramente un cambio de mentalidad:

Bueno definitivamente todo es gracias al cambio de mentalidad de las personas, antes era demasiado machista el pensamiento pero definitivamente nos hemos dado cuenta, me incluyo, de que definitivamente las mujeres tienen un campo donde se desarrollan más o simplemente con el hombre complementan y sacan adelante proyectos excelentes, ideas hacen muy buenas ideas, entonces nos damos cuenta de que simplemente la complementación o la sinergia dan excelentes resultados (GFA4).

\footnotetext{
${ }^{34}$ Integrante del GFA2a.
} 
Si bien hay avances en cambios de mentalidad y mayor acceso de la mujer al mercado laboral, simultáneamente se mantiene la tensión entre una visión apegada al rol tradicional de la mujer: "... la misma pobreza hace pensar a las mujeres que deben buscar marido y se casen pensando que van a tener una mejor vida"35. Por otro lado, la participación del hombre en los aspectos domésticos es incipiente y tanto chicos como chicas aún miran varias funciones como propias de la mujer.

\section{Discriminación en las experiencias laborales}

A más de la discriminación por ser jóvenes que ya ha sido mencionada, hay otras dos que refieren. La una dada por la pertenencia a la población afroecuatoriana y dice del fuerte racismo existente:

El maltrato que tenemos de la Ley, ya nos ven caminando por ahí nos golpean. Algunos nos dicen pásame las botas, si no partidos la boca. Uno va caminando y te dicen no te muevas si no te meto un patazo (GFA1).

Yo he trabajado con mi mami, ella hace encebollados, caldo de salchicha, comidas variables, hacía los fines de semana, pero pasa que a nosotros nos fue fatal porque en la ciudadela que nosotros vivimos hay vecinos como que no les gusta el color de nuestra piel. Parece que son racistas, porque nosotros salíamos a vender otros veían y les daba asco en realidad decía esa señora cocina rico, pero algunas por maldad hacían cualquier cosa para que a nosotros nos vaya mal en el negocio. Pues mi mami tra-

${ }^{35}$ Integrante del GFA2b. 
taba de salir, pues yo al ver la reacción de las personas yo me he sentido mal porque soy de las personas que me dicen algo que me ofende yo enseguidita me resiento porque soy muy sentimental. Hubo un tiempo en que yo no le ayudé a mi madre y ella solita se sacó la madre trabajando ella sola y yo en cambio me sentía mal, pero también me daba coraje con esa gente que por el tipo de piel ellos no nos compren. Yo no entiendo que personas son esas y eso es lo que me ha rebajado los ánimos de trabajar. Si así es con una simple comida como va a ser cuando me toque conseguir un trabajo. Entonces me viene la idea que a futuro quizá no tenga trabajo o me vaya mal, como le digo si en esta situación nos va mal, peor en el futuro (GFA2b).

La otra forma de discriminación es por la orientación sexual:

Todas las noches, tanto homosexuales como travestis, tanto gay como travestis terminan pidiendo trabajo sexual porque no tienen trabajo, porque no hay plazas de trabajo, porque no hay el chico gay que no termine haciendo el trabajo sexual, el travesti termina haciendo el trabajo sexual porque no hay [trabajo] y con el problema de la migración que actualmente existe...! Ahora, mucho peor (GFB3).

La discriminación por la condición socioeconómica, que en forma constante han mencionado en sus relatos, se entrecruza con las dos anteriores, agravando la situación de afectación de derechos. 


\section{¿Cómo miran la educación?}

Hay una visión negativa compartida de los jóvenes respecto del sistema educativo del país: a) la califican como deficiente, de mala calidad, no actualizada y con cosas inútiles: b) no garantiza el acceso a todas las personas; c) cada vez es más costosa y son muchos años; d) la formación no está orientada a ser buenos profesionales; e) faltan carreras nuevas; y, f) no facilita la vinculación al mundo del trabajo.

A pesar de dichos límites, consideran que el 'tener estudios' es una pieza necesaria para la ubicación laboral posterior "... los jóvenes que no tienen la oportunidad de un estudio superior e incluso de un estudio secundario, se dedican al trabajo simplemente para sobrevivir, ya sea trabajo de albañiles, electricista, carpinteros, en fin..." ${ }^{36}$. La aspiración es tener una 'buena educación': “... tenemos que estar bien preparados para que nos puedan dar un trabajo, porque hay personas, que al no ser capacitadas andan sin trabajo..." ${ }^{\prime 7}$. Para ello, el sistema vigente debería cambiar "me gustaría que el sistema educativo de aquí del Ecuador cambie lo que es... "38

Uno de los cambios es respecto al tipo de oferta de las Universidades, que debería estar en sintonía con la dinámica del mercado y la ciudad:

Lo que es la técnica, la ingeniería, porque se ve la ciudad, el país va aumentando en lo que es tecnología, técnica, están preparando malecones, hoteles, todo, entonces en esa parte la técnica es la que está avanzando, y también lo que es o sea técnicos que

\footnotetext{
${ }^{36}$ Integrante del GFA3.

${ }^{37}$ Integrante del GFA2a.

${ }^{38}$ Integrante del GFA2b.
} 
se preocupan más del medio ambiente, o sea no, técnicos ya que hagan fábricas y contaminen, sino técnicos que tratan de solucionar esa contaminación (GFA2a).

También ubican que en el campo de ventas hay demanda, pero que estas actividades no son de interés de la mayor parte y es vista como un espacio transitorio:

En los periódicos si usted revisa de 15 anuncios 13 son de ventas y dos será de tipo administrativo, pero ventas es una carrera que a pocas personas les gusta ahora recién se está comenzando carreras en ventas, todavía es considerado si no hay más trabajo nos vamos a ventas, aunque es una de las plazas que más puede percibir, va en relación hacia tu sacrificio si mientras más trabajas más ganas, pero a pesar de eso no se lo concibe como un empleo deseado, sino como un empleo que ya no podría tener acceso a otro y hasta que consiga algo mejor voy ha $\operatorname{ver}($ GFA4).

Las pasantías y prácticas son vistas como importantes, pero que deberían estar organizadas de otra manera, como parte de los programas de estudio y que sean un espacio de real aprendizaje de las actividades laborales: “... cuando eres practicante y estás en el colegio te mandan enseguida a archivar en vez de enseñarte..." ${ }^{39}$ y que no deberían ser gratuitas: "... o sea trabajar gratis, no estoy de acuerdo en eso..."

Además, la generalidad de jóvenes busca realizar otros cursos que les permita contar con mayores destrezas. Inglés y computación son los más ubicados en el momento actual:

\footnotetext{
${ }^{39}$ Integrante del GFA4.

${ }^{40}$ Integrante del GFA3. 
Por eso siempre es necesario capacitarse en otras cosas, puede ser inglés; yo estoy estudiando ahora inglés, yo no lo quiero como una carrera, sino más bien como un medio auxiliar. Todos ahora deberían hablar inglés porque es algo indispensable porque la realidad del mundo se desenvuelve en inglés que es el idioma que ahora está predominando (GFA2b).

Para lograr los cambios miran que debe haber una voluntad de las autoridades y establecer estrategias conjuntas con colegios, universidades, sectores productivos, financieros e instituciones que apoyan con proyectos.

También para la propia juventud se plantean cambios porque hay pensamientos, sentimientos y actitudes de rechazo o aceptación pasiva del estudio:

...me va a parecer que si además ponen algo educativo, ponen algo por aprender y nos va a parecer aburrido, y voy, prefiero escuchar música, hacer otra cosa, que ponerme a ver algo que, según ellos me van a dar para que yo lo aprenda, pero yo lo veo aburrido, entonces el punto es que lo educativo es lo malo, muchas de las veces, habría que cambiar esa manera de pensar en los jóvenes de lo que se está enseñando es aburrido o que estoy estudiando porque mis padres me están poniendo a estudiar, no estudia porque uno quiere sino que porque ya, me están poniendo a estudiar ya, entonces si me van a enseñar, en la mentalidad, este de chicos que me van a enseñar algo, no me gusta, sino van a perder eso, ósea de poner un programa, y no yo prefiero ir a hacer otra cosa que atender ese programa que me va a hacer bien, pero yo no quiero (GFA22a). 
Hay otros chicos que el estudio es parte funcional de otra meta "... mi papá es el dueño de una empresa, lo único que yo estudio, es para hacerme cargo de la empresa, facilidad yo si tengo" ${ }^{\prime \prime}$.

\section{¿Qué proponen?}

La mayor parte de jóvenes participantes conocen poco de programas específicos de apoyo a la juventud para su inserción laboral, mencionan los de la Cámara de Comercio de Guayaquil y de sectores de Iglesia. Además perciben que hay poco apoyo a los grupos de estratos bajos, especialmente la niñez:

...porque uno de los problemas más grandes es la desatención que hay para los niños, muchos niños que trabajan desde muy chiquitos que están en la calle y lo que vamos ha conseguir de esa juventud es que en el futuro sean adolescentes rebeldes, ladrones y resentidos con la sociedad por lo que no pueden tener. Deberían preocuparse mucho por la juventud, ya más que incentivar cualquier otro tipo de inversión dentro del país, es el momento de rescatar a la niñez finalmente va hacer lo que nos va ayudar a triunfar a ir saliendo como país (GFA4).

Las alternativas planteadas están centradas en una necesidad de cambios, se pueden ubicar dos grandes niveles, el primero que demandan acciones a distintos sectores y el segundo sobre su rol en los cambios que esperan. Respecto al primer nivel, las principales demandas son las siguientes:

Una primera, planteada por los chicos que se encuentran marginados y excluidos, es directa y de corte

\footnotetext{
${ }^{41}$ Idem.
} 
más asistencial a la par de un reconocimiento como personas: "(que nos den) todo... que nos den trabajo y que uno valga ante la autoridad"

Hacia las empresas las propuestas de los jóvenes se dirigen en el sentido de a) creación de fuentes de empleo, b) reconocimiento de que la juventud puede desempeñarse bien en los trabajos, acompañado de una normativa de respaldo y promoción, y c) creación de oportunidades de entrenamiento, que implican forman distintas de capacitación o pasantías:

Por ejemplo que en las empresas importantes haya un grado de juventud, no solamente que trabaje gente con experiencia porque uno también necesita ganar experiencia y que en cada empresa haya una ley para que podamos trabajar así la gente joven (GFA2b).

(para empleadores) Si no le da estabilidad si no le da seguridad si no hay apoyo si no lo valora, capacita, motiva, no va tener un buen potencial (GFA4).

Dentro de las mismas empresas crear como un centro de capacitación para los jóvenes, por ejemplo nosotros que recién salimos, hacer una especie de pequeña Universidad dentro de cada empresa, o sea que por ejemplo en lo que produce por ejemplo una fábrica, capacitar a las personas que desean trabajar en eso en cada empresa, capacitarnos más, incluso lo que están pidiendo las empresas ahorita es gente joven, porque la gente joven ya rinde más (GFA2a).

Modelos de otros lados inciden en las percepciones y propuestas de la juventud, esperarían que el gobierno central impulse acciones de protección:

\footnotetext{
${ }^{42}$ Integrantes del GFA1.
} 
Por ejemplo en otros lados como en EE.UU. Ios adolescentes trabajan libremente. Ellos se organizan dicen vamos a limpiar carros, etc.; en las películas se ve que nadie las discrimina, nadie abusa de ellas, trabajan como niñeras. Es el gobierno que los protege, que los apoya. Sería bonito que aquí en Ecuador podamos trabajar sin ser discriminados, sin sufrir ningún acoso ni nada de eso. Cuando yo he visto eso en aquellos países me pregunto cómo harán. Fuera lindo que aquí en Ecuador también se diera eso (GFA2b).

Cuba, por ejemplo, es un país más pobre que nosotros, pero tiene un sistema de educación fuerte. Cuba tiene una canasta familiar básica, pero ellos tienen que tratar de sobrevivir, viven del turismo. Ellos, tienen educación tremenda en lo que es la medicina (GFA2b).

Hacia el gobierno y las autoridades, hay varias referencias, en torno a estructurar programas de apoyo y combatir formas de corrupción:

Parar un poco eso de tanto palanqueo, porque hay personas que están allá y no saben nada, ni un rábano de lo que ejercen su profesión (GFA3).

Los medios de comunicación son ubicados como un espacio importante y esperarían que asuman acciones en torno a promover espacios educativos:

... lo poco que veo de repente son esos canales de televisión que pasan digamos programas de diversión, o sea, doy un ejemplo como A Todo Dar, en vez de digamos, ese mismo canal, en vez de, todo ese tiempo que pasan el programa, ubicar un programa educativo para, digamos todas esas personas, todos esos jóvenes que no tienen 
digamos en la tarde nada qué hacer vean, aprendan... (GFA2a).

El tema de la educación plantea varios desafíos. Como se ubicó anteriormente, hay un cuestionamiento respecto de que los establecimientos secundarios y superiores no están respondiendo de la mejor manera a los cambios globales y del mercado de trabajo:

Yo creo que por lo menos para la clase media baja que ahora no tienen acceso a la educación, crear institutos técnicos, donde les enseñan a desarrollar ciertas actividades que luego hasta el propio gobierno se pudo haber beneficiado por ejemplo si crea un programa, para cultivo de tierras... (GFA4).

Se ubica también que las iniciativas deben dirigirse a sectores más afectados:

Primeramente capacitación a nivel de lo que es el estudio para ellos (sectores con menos recursos), o sea darles más facilidades para que adquieran el conocimiento, porque realmente las universidades ahora son caras, incluyendo las del Estado, ayudarlos, el Estado lo más posible para que puedan adquirir un nivel universitario (GFA3).

Hay que darle más dignidad a las personas en la parte de lo que es la pobreza mucha gente que vive en la calle sus casas ya un poco más ya es un palillo de pólvora que está a punto (de estallar)... Nos ayuden a fomentar el tema de la dignidad a aquellas personas que por sí solas no la pueden conseguir. Yo pienso en una parte de hacer una campaña o invertir, hacerles casas y que ellos trabajen también a cambio por lo que 
vayan a pagar por la casa, la educación de los niños/as, la nutrición o sea todas aquellas cosas que realmente fomentan la pobreza pero son necesarias por la dignidad de las personas (GFA4).

En cuanto al segundo nivel los jóvenes se miran frente a un sistema en donde priman relaciones de poder basado en el dinero, frente al cual, como jóvenes carecen de poder y no hay liderazgo:

Para cambiar el país principalmente como todo jefe organiza su empresa y tiene una buena administración, el jefe de nosotros se podría decir aquí en la Tierra, en país, sería nuestro presidente no, y yo creo que desde ahí tendríamos que empezar a cambiar, pero si nos ponemos a pensar un poco, para poder cambiar ese tipo de personas uno necesita tener dinero no, nos damos cuenta de que en este país, para hacer algo se necesita dinero y todas esas personas que están ahí al mando, son gente de poder económico, o sea por mi lado, yo creo que haría puntos no más, es muy difícil tratar de cambiarlo así, si no tenemos el poder en nuestras manos, el poder en ese caso el dinero, sería muy difícil cambiar, el tema de nuestro país siempre ha sido así, o sea, si yo voy a cambiar el país, pero si no veo que otra persona, o sea, sí arriesga a hacer eso yo no lo podría hacer, tengo que esperar a que alguien trate de hacer algo para yo ir atrás, o sea no hay buenos líderes aquí me parece (GFA2a).

En términos más personales plantean: Dejar la droga, los vicios y seguir adelante, así cambia la situación (GFA1). 
Debemos unirnos y no dejarnos explotar por los demás. Esto depende de la unión, pensar con la cabeza y no con los pies. Pensar en qué vamos a hacer por el futuro del Ecuador (GFA2b).

O sea, la cosa no es que, por ejemplo el país va mal, nosotros vamos a ir peor, la cosa es nosotros tratar de salir adelante, ser mejor en cada día y ser alguien, en esos 15 años tratar de arreglar la cosa, aunque sea no para los demás sino aunque sea para con nosotros, para con los que viven con nosotros, o sea mirar en nuestro entorno más que todo, y en conjunto para poder ayudar si se quiere se puede ayudar en conjunto también, porque eso también es verdad, porque cada día, cada año escuchamos a las personas quejarse de la situación, el país que está mal y todo, o sea lo que las personas hacen es quejarse, nadie se pone a pensar un momento, un minuto por lo menos, para ver cómo salimos de donde estamos (GFA2a).

Finalmente, podríamos cerrar con esta interrogante y demanda:

Puede ser que a veces nosotros tengamos la culpa tal vez sea que estos problemas salgan del núcleo del hogar, pero sería bueno que nosotros podamos ser más protegidos por el gobierno para poder hacer algo. Si nosotros vamos a representar a la nación, ¿qué le vamos a dar a la gente del futuro? Vamos a enseñar lo mismo que a nuestras generaciones, algún día tendremos que ser padres, habrá más niñas y niños (GFA2b). 
